\title{
Uso dA ÁGUa em BIótIPOS de AZEvÉm (Lolium multiflorum) EM CONDIÇÃo de COMPETIÇÃO ${ }^{1}$
}

\author{
Water Use in Italian Ryegrass (Lolium multiflorum) Biotypes under Competition \\ CONCENÇO, G. ${ }^{2}$, FERREIRA, E.A. ${ }^{2}$, SILVA, A.A. ${ }^{3}$, FERREIRA, F.A. ${ }^{3}$, VIANA, R.G. ${ }^{2}$, \\ D'ANTONINO, L. ${ }^{2}$, VARGAS, L. ${ }^{4}$ e FIALHO, C.M.T. ${ }^{5}$
}

\begin{abstract}
RESUMO - Objetivou-se com este trabalho avaliar as características associadas à eficiência de uso da água em biótipos de azevém resistente e suscetivel ao glyphosate, em diferentes niveis de competição. O experimento foi realizado em esquema fatorial $2 \times 5$, com os dois biótipos de azevém, suscetível e resistente, em planta única no centro da parcela, competindo com 0, 1, 2, 3 e 4 plantas do biótipo oposto. Todas as características - matéria seca da parte aérea (MSPA), condutância estomática (Gs), pressão de vapor na câmara subestomática $\left(E_{a n}\right)$, gradiente entre temperatura da folha e do ar $(\Delta T)$ e taxa de transpiração $(E)$ - foram avaliadas 50 dias após a emergência das plantas, sendo calculada também a eficiência do uso da água (WUE) pela relação entre a quantidade de $\mathrm{CO}_{2}$ fixado pela fotossintese e a quantidade de água transpirada. Foi elaborada ainda uma matriz de correlação entre as variáveis. O biótipo suscetível apresentou maior acúmulo de MSPA, comparado ao biótipo resistente ao glyphosate, quando cultivado livre ou em competição, porém foi menos eficiente quanto ao uso da água.
\end{abstract}

Palavras-chave: resistência a herbicidas, glyphosate, competição.

\begin{abstract}
The objective of this work was to evaluate the characteristics associated to water use efficiency in ryegrass biotypes resistant and susceptible to glyphosate, under different competition levels. The trial was installed in factorial scheme $(2 \times 5)$, with one plant of the studied biotype alone at the center of the plot, under competition against $0,1,2,3$ and 4 plants of the opposite biotype. The variables (shoot dry matter (MSPA), watervapor stomatal conductance (Gs), water vapor pressure from the leaf chamber $\left(E_{\text {an }}\right)$, leaf and air temperature difference $(\Delta T)$ and transpiration rate (E)) were evaluated 50 days after emergence, with water use efficiency (WUE) being obtained by the relation between the amount of $\mathrm{CO}_{2}$ fixed by photosynthesis and the corresponding transpired water. A correlation table was built between all evaluated variables. The biotype susceptible to glyphosate accumulated dry matter more efficiently than the resistant one, when growing both alone or under competition. On the other hand, the biotype susceptible to glyphosate is less efficient in water use.
\end{abstract}

Keywords: herbicide resistance, glyphosate, competition.

1 Aceito para publicação em 17.11.2006 e na forma revisada em 12.6.2007.

2 Eng ${ }^{0}$-Agr ${ }^{\circ}$, Doutoran do em Fitotecnia da Universidade Federal de Viçosa - UFV, 36570-000 Viçosa-MG; ${ }^{3}$ D.Sc., Professor do Dep. de Fitotecnia - UFV; ${ }^{4}$ D.Sc., Pesquisador da Embrapa Trigo, Caixa Postal 451, 99001-970, Passo Fundo-RS; ${ }^{5}$ Acadêmica do curso de Agronomia da UFV. 


\section{INTRODUÇÃO}

O azevém é importante espécie daninha nas culturas de trigo ou soja em sucessão (Roman et al., 2004), ocorrendo também em pomares de macieira e pereira nas regiões produtoras dessas frutas (Vargas et al., 2004). Nos últimos anos, os produtores vêm observando redução na resposta do azevém a tratamentos com glyphosate, sendo bastante comum a ocorrência de plantas de azevém que não manifestam sintomas de intoxicação após tratadas com doses elevadas desse herbicida. Esse comportamento indicava possibilidade do aparecimento da resistência ao glyphosate, o que foi confirmado por Vargas et al. (2004).

A competição afeta quantitativa e qualitativamente a produção, pois modifica a eficiência de aproveitamento dos recursos do ambiente, como água, luz e nutrientes (Sinclair et al., 1975; Melo et al., 2006), estabelecendo-se entre a cultura e as plantas de outras espécies existentes no local. Essa competição ocorre também entre indivíduos de uma mesma espécie ou entre biótipos predominantes na área, conforme constatado por Ferreira et al. (2006), os quais verificaram que biótipos de azevém resistentes ao glyphosate possuem menor capacidade competitiva do que os suscetiveis.

Embora a água seja abundante na terra, menos de $1 \%$ é água doce apta para o consumo humano e para utilização na agricultura. Além disso, a água de boa qualidade disponivel não está distribuída uniformemente. A eficiência do uso da água é caracterizada como a quantidade de água evapotranspirada por uma cultura para a produção de certa quantidade de matéria seca. Assim, culturas mais eficientes no uso da água produzem mais matéria seca por grama de água transpirada. A soja, por exemplo, necessita de $750 \mathrm{~g}$ de água por g de matéria seca acumulada, enquanto o arroz irrigado necessita de $4.700 \mathrm{~g}$ de água por g de massa seca acumulada (Baptista et al., 2001). O uso mais eficiente da água está diretamente relacionado ao tempo de abertura estomática, pois, enquanto a planta absorve $\mathrm{CO}_{2}$ para a fotossintese, a água é perdida por transpiração, com intensidade variável, dependendo do gradiente de potencial entre a superficie foliar e a atmosfera, seguindo uma corrente de potenciais hídricos (Pereira-Netto et al., 2002). A escolha de cultivares mais eficientes na agricultura pode auxiliar na conservação desse recurso e também na redução do uso da água potável global na produção de alimentos (Baptista et al., 2001).

Quando plantas estão submetidas à alta competição, as características fisiológicas do crescimento e desenvolvimento normalmente são alteradas, o que resulta em diferenças no aproveitamento dos recursos do ambiente, principalmente no uso da água, que influencia de modo direto a disponibilidade de $\mathrm{CO}_{2}$ no mesofilo foliar e a temperatura da folha e, conseqüentemente, a eficiência fotossintética da planta.

Objetivou-se com este trabalho avaliar as características associadas à eficiência de uso da água em biótipos de azevém resistente e suscetivel ao glyphosate, em diferentes niveis de competição.

\section{MATERIAL E MÉTODOS}

O experimento foi instalado em casa de vegetação com irrigação por nebulização, em delineamento experimental fatorial $2 \times 5$, com quatro repetições. As unidades experimentais constaram de vasos de $5 \mathrm{~L}$ de substrato (mistura pré-elaborada de solo e terra vegetal, corrigida e adubada de acordo com análise de solo). Os tratamentos constaram de plantas dos biótipos de azevém resistente e suscetivel ao glyphosate. No centro da unidade experimental, foram semeadas três sementes do biótipo de azevém, considerado como o tratamento da unidade experimental ( $\mathrm{R}$ para resistente e S para suscetivel), enquanto na periferia da unidade experimental foram semeadas 10 sementes do biótipo oposto ao do tratamento (central).

As plântulas se desenvolveram por 10 dias após a emergência, quando então se efetuou o desbaste. Os tratamentos consistiam em manter apenas uma planta de determinado biótipo no centro da unidade experimental, variando na periferia as densidades de plantas do biótipo oposto (uma planta do biótipo resistente ou suscetível no centro competindo com 0, 1, 2, 3 e 4 plantas do biótipo oposto na periferia). A área de semeadura do biótipo central da unidade experimental foi delimitada por um 
círculo de $4 \mathrm{~cm}$ de diâmetro por $2 \mathrm{~cm}$ de profundidade, que possibilitou a identificação da planta central adulta, juntamente com os respectivos perfilhos, sem interferir na competição do biótipo central com as demais plantas da periferia, tanto na parte aérea como no sistema de raizes.

As unidades experimentais foram mantidas eqüidistantes, de forma que a área de superficie disponivel para o desenvolvimento das plantas correspondesse à área da unidade experimental. As plantas se desenvolveram por 50 dias após a emergência, quando então foram realizadas as avaliações, no terço médio da primeira folha completamente expandida do perfilho principal das plantas de azevém. Foi utilizado um analisador de gases no infravermelho (IRGA), marca ADC, modelo LCA 4 (Analytical Development Co. Ltd, Hoddesdon, UK), em casa de vegetação aberta, permitindo livre circulação do ar. A parte aérea das plantas também foi coletada e o material seco em estufa de circulação forçada de ar, sendo pesados em balança analítica, onde se obteve a variável massa seca da parte aérea (MSPA). Cada bloco foi avaliado em um dia, entre 8 e 10 horas da manhã, de forma que mantivesse as condições ambientais homogêneas durante a avaliação. Foram avaliadas a planta central e uma planta periférica escolhida ao acaso em cada unidade experimental.

Foram avaliados a condutância estomática de vapores de água ( $\mathrm{Gs}-\mathrm{mol} \mathrm{m}^{-1} \mathrm{~s}^{-1}$ ), a pressão de vapor na câmara subestomática $\left(\mathrm{E}_{\mathrm{an}}-\mathrm{mBar}\right)$, o gradiente entre temperatura da folha e do ar $(\Delta \mathrm{T})$ e a taxa de trans piração $\left(\mathrm{E}-\mathrm{mol} \mathrm{H}_{2} \mathrm{O} \mathrm{m}^{-2} \mathrm{~s}^{-1}\right.$ ), sendo calculada ainda a eficiência do uso da água (WUE - $\mathrm{mol} \mathrm{CO}_{2} \mathrm{~mol}$ $\mathrm{H}_{2} \mathrm{O}^{-1}$ ) a partir dos valores de quantidade de $\mathrm{CO}_{2}$ fixado pela fotossintese e quantidade de água transpirada. Foi elaborada ainda a matriz de correlação entre as variáveis.

Os dados foram submetidos à análise de variância pelo teste $\mathrm{F}$ a $5 \%$ de probabilidade, sendo efetuado teste de Duncan a $5 \%$, para avaliar o efeito do aumento na densidade de plantas, e teste da Diferença Mínima Significativa (DMS) a 5\% de probabilidade, para avaliar diferenças entre o biótipo resistente e o suscetivel em cada tratamento (Pimentel-Gomes, 1987).

\section{RESULTADOS E DISCUSSÃO}

O biótipo suscetivel apresentou maior acúmulo de MSPA, comparado ao biótipo resistente ao glyphosate, quando cultivado livre ou em competição com plantas do biótipo oposto. Por outro lado, quando em competição entre plantas do mesmo biótipo, o resistente mostrou maior acúmulo de MSPA do que o suscetivel em todas as densidades, provavelmente devido à menor competição entre as plantas, em razão do menor acúmulo de massa característico do biótipo resistente (Tabela 1).

Tabela 1 - Massa seca da parte aérea (MSPA) dos biótipos resistente e suscetível ao glyphosate em condição de competição

\begin{tabular}{|c|c|c|c|}
\hline \multirow{2}{*}{$\begin{array}{l}\text { Posição e número } \\
\text { de plantas }\end{array}$} & \multicolumn{2}{|c|}{ Biótipo de azevém } & \multirow{2}{*}{ Diferença ${ }^{1 /}$} \\
\hline & Resistente & Suscetível & \\
\hline Centro $^{3 /}$ & \multicolumn{3}{|c|}{ MSPA - g planta ${ }^{-1}$} \\
\hline $1(0)$ & $12,92 \mathrm{a}^{2 /}$ & $18,09 \mathrm{a}$ & $-5,17 n s$ \\
\hline $1(1)$ & $8,29 a b$ & $8,85 \mathrm{~b}$ & $-0,56 n s$ \\
\hline $1(2)$ & $4,23 \mathrm{~b}$ & $6,10 \mathrm{~b}$ & $-1,86 \mathrm{~ns}$ \\
\hline $1(3)$ & $3,72 \mathrm{~b}$ & $7,05 \mathrm{~b}$ & $-3,32 \mathrm{~ns}$ \\
\hline $1(4)$ & $3,67 \mathrm{~b}$ & $8,14 \mathrm{~b}$ & $-4,47 \mathrm{~ns}$ \\
\hline \multicolumn{4}{|l|}{ Externas $^{4 /}$} \\
\hline $0(1)$ & - & -- & - \\
\hline $1(1)$ & $14,03 \mathrm{a}$ & $8,72 \mathrm{a}$ & $+5,31 \mathrm{~ns}$ \\
\hline $2(1)$ & $10,84 \mathrm{ab}$ & $2,61 \mathrm{a}$ & $+8,23 * *$ \\
\hline $3(1)$ & $7,88 \mathrm{ab}$ & $3,16 \mathrm{a}$ & $+4,73 \mathrm{~ns}$ \\
\hline $4(1)$ & $5,63 \mathrm{~b}$ & $3,35 \mathrm{a}$ & $+2,29 \mathrm{~ns}$ \\
\hline \multicolumn{4}{|c|}{$\begin{array}{l}{ }^{\cup} \text { ns }=\text { não-significativo; } * \text { significativo a } 5 \% ; * * \text { significativo a } 1 \% \mathrm{~d} \\
\text { probabilidade pelo teste da DMS. }\end{array}$} \\
\hline \multicolumn{4}{|c|}{$\begin{array}{l}\text { Médias seguidas da mesma letra, na mesma coluna e dentro de cada posição } \\
\text { (centro ou externas), não diferem pelo teste de Duncan a } 5 \% \text { de probabilidade. }\end{array}$} \\
\hline \multicolumn{4}{|c|}{$\begin{array}{l}\text { 3/ Centro: número de plantas do biótipo indicado no centro da parcela, } \\
\text { competindo com o número de plantas entre parênteses do biótipo oposto. }\end{array}$} \\
\hline
\end{tabular}

A condutância estomática dos vapores de água (Gs) não se alterou com o aumento da densidade de plantas do biótipo oposto, tanto para o suscetivel como para o resistente. Por outro lado, quando as plantas do biótipo suscetivel foram submetidas à competição entre si, observou-se aumento na condutância estomática (Tabela 2), provavelmente devido ao incremento na atividade metabólica da planta, como forma de favorecer o aumento da massa e da competitividade desta planta em relação às demais. A condutância foliar é composta em 
Tabela 2 - Condutância estomática (Gs) dos biótipos resistente e suscetível ao glyphosate em condição de competição

\begin{tabular}{|c|c|c|c|}
\hline \multirow{2}{*}{$\begin{array}{l}\text { Posição e número } \\
\text { de plantas }\end{array}$} & \multicolumn{2}{|c|}{ Biótipo de azevém } & \multirow{2}{*}{ Diferença $^{\mathrm{L}}$} \\
\hline & Resistente & Suscetível & \\
\hline Centro $^{3 /}$ & \multicolumn{3}{|c|}{ Gs - $\mathrm{mol} \mathrm{m}^{-1} \mathrm{~s}^{-1}$} \\
\hline $1(0)$ & $0,108 \mathrm{a}^{2 /}$ & $0,180 \mathrm{a}$ & $-0,072 \mathrm{~ns}$ \\
\hline $1(1)$ & $0,130 \mathrm{a}$ & $0,125 \mathrm{a}$ & $+0,005 \mathrm{~ns}$ \\
\hline $1(2)$ & $0,128 \mathrm{a}$ & $0,135 \mathrm{a}$ & $-0,007 \mathrm{~ns}$ \\
\hline $1(3)$ & $0,083 \mathrm{a}$ & $0,150 \mathrm{a}$ & $-0,067 \mathrm{~ns}$ \\
\hline $1(4)$ & $0,048 \mathrm{a}$ & $0,148 \mathrm{a}$ & $-0,100 *$ \\
\hline \multicolumn{4}{|l|}{ Externas $^{4 /}$} \\
\hline $0(1)$ & -- & -- & -- \\
\hline $1(1)$ & $0,183 \mathrm{a}$ & $0,085 \mathrm{~b}$ & $+0,098 *$ \\
\hline $2(1)$ & $0,230 \mathrm{a}$ & $0,093 \mathrm{ab}$ & $+0,137 *$ \\
\hline $3(1)$ & $0,178 \mathrm{a}$ & $0,125 \mathrm{ab}$ & $+0,053 \mathrm{~ns}$ \\
\hline $4(1)$ & $0,130 \mathrm{a}$ & $0,205 \mathrm{a}$ & $-0,075 \mathrm{~ns}$ \\
\hline
\end{tabular}

$\stackrel{1}{1}$ ns - não-significativo; * significativo a $5 \%$; ** significativo a $1 \%$ de probabilidade pelo teste da DMS

$\stackrel{2}{2}$ Médias seguidas da mesma letra, na mesma coluna e dentro de cada posição (centro ou externas), não diferem pelo teste de Duncan a 5\% de probabilidade.

3/ Centro: número de plantas do biótipo indicado no centro da parcela, competindo com o número de plantas entre parênteses do biótipo oposto.

${ }^{4 /}$ Externas: número de plantas do biótipo indicado, competindo entre si e com a planta do biótipo oposto (1) no centro da parcela.

pequena parte pela condutância cuticular da epiderme e, quando os estômatos estão abertos, pela Gs, que é controlada pelas célulasguarda dos estômatos. Assim, a Gs é proporcional ao número e tamanho dos estômatos e ao diâmetro da abertura do estômato, características que dependem de outros fatores endógenos e ambientais (Brodribb \& Holbrook, 2003).

O teste da DMS mostrou que a Gs foi superior em plantas suscetiveis competindo com quatro plantas do biótipo resistente. Por outro lado, quando o biótipo suscetivel se encontrava em maior densidade (periferia), mostrou condutância estomática de vapor de água igual ou inferior à observada nas plantas do biótipo resistente no centro da parcela (Tabela 2). Isso provavelmente se deve ao fato de que uma única planta do biótipo resistente não é capaz de provocar incremento no metabolismo das plantas do biótipo suscetivel (Tabela 2). O controle de abertura e fechamento dos estômatos depende de uma série de fatores, como radiação solar, nível de $\mathrm{CO}_{2}$ no mesofilo, umidade relativa (déficit de pressão de vapor do ar), potencial hídrico e outros de menor magnitude, como vento, substâncias de crescimento e ritmos endógenos próprios de cada espécie. Conseqüentemente, a combinação de populações de plantas resistentes e suscetiveis pode apresentar várias influências que atuam na Gs. A planta suscetivel foi capaz de incrementar a condutância estomática somente quando estava isolada e competindo com grande número de plantas do biótipo resistente, de menor capacidade competitiva (Vargas et al., 2005; Ferreira et al., 2006).

A pressão de vapor na câmara subestomática $\left(\mathrm{E}_{\mathrm{an}}\right)$ não diferiu para biótipo resistente e suscetivel em nenhum dos tratamentos, de acordo com o teste da DMS (Tabela 3). Quando as plantas foram submetidas à maior competição (uma planta no centro com o aumento da densidade do biótipo oposto na periferia), também se comportaram de forma similar, em razão do aumento na pressão de vapor na câmara subestomática. Com relação às plantas localizadas na periferia, o comportamento foi similar em função do aumento da competição. $\mathrm{A} \mathrm{E}_{\text {an }}$ está diretamente relacionada ao status hídrico da planta e à dinâmica de fluxo de vapor de água. Mesmo em uma folha transpirando rapidamente, a umidade relativa na câmara poderá exceder $95 \%$, e o potencial hídrico resultante pode estar próximo de zero, incrementando as trocas com o meio ambiente, que possui potencial hídrico muito negativo. Nessas condições, a pressão de vapor seria a pressão de vapor de saturação na temperatura da folha. Dessa forma, a $\mathrm{E}_{\text {an }}$ é controlada pelo nivel de umidade e temperatura da folha, atuando sobre a condutância estomática de vapores de água (Gs) e sobre a transpiração (E).

O metabolismo do vegetal causa incremento na temperatura da folha, de forma que, via de regra, a temperatura da folha é superior à do ar ao seu redor. Assim, incrementos no metabolismo podem ser indiretamente aferidos em função do gradiente entre temperatura da folha e do ar $(\Delta \mathrm{T})$. Normalmente essa diferença é de somente um ou dois graus, mas, em casos extremos, pode exceder $5^{\circ} \mathrm{C}$ (Drake \& Salisbury, 1972; Atkin et al., 2000). Uma vez que a $\Delta \mathrm{T}$ não mostrou significância estatística, pode-se concluir que o metabolismo não foi seriamente afetado e que esse fator provavelmente possa ser excluído da participação na Gs. O valor médio de $\Delta \mathrm{T}$ observado neste trabalho foi de $1,21^{\circ} \mathrm{C}$ (Tabela 4). 
Tabela 3 - Pressão de vapor na câmara subestomática $\left(\mathrm{E}_{\mathrm{an}}\right)$ dos biótipos resistente e suscetível ao glyphosate em condição de competição

\begin{tabular}{|c|c|c|c|}
\hline \multirow{2}{*}{$\begin{array}{c}\text { Posição e número } \\
\text { de plantas }\end{array}$} & \multicolumn{2}{|c|}{ Biótipo de azevém } & \multirow{2}{*}{ Diferença $^{\underline{ }}$} \\
\cline { 2 - 3 } & Resistente & Suscetível & \\
\hline Centro $^{\text {3l }}$ & \multicolumn{3}{|c|}{ Ean- mBar } \\
\hline $1(0)$ & $52,68 \mathrm{~b}^{\underline{2}}$ & $57,99 \mathrm{~b}$ & $-5,31 \mathrm{~ns}$ \\
\hline $1(1)$ & $60,59 \mathrm{ab}$ & $63,03 \mathrm{ab}$ & $-2,44 \mathrm{~ns}$ \\
\hline $1(2)$ & $69,64 \mathrm{ab}$ & $68,11 \mathrm{ab}$ & $+1,53 \mathrm{~ns}$ \\
\hline $1(3)$ & $67,89 \mathrm{ab}$ & $69,62 \mathrm{ab}$ & $-1,73 \mathrm{~ns}$ \\
\hline $1(4)$ & $77,71 \mathrm{a}$ & $78,88 \mathrm{a}$ & $-1,17 \mathrm{~ns}$ \\
\hline Externas $^{4 \prime}$ & & & -- \\
\hline $0(1)$ & -- & -- & $-6,34 \mathrm{~ns}$ \\
\hline $1(1)$ & $55,06 \mathrm{a}$ & $61,40 \mathrm{a}$ & $-1,31 \mathrm{~ns}$ \\
\hline $2(1)$ & $60,43 \mathrm{a}$ & $73,53 \mathrm{a}$ & $+1,47 \mathrm{~ns}$ \\
\hline $3(1)$ & $65,58 \mathrm{a}$ & $64,11 \mathrm{a}$ & $-17,74 \mathrm{~ns}$ \\
\hline $4(1)$ & $61,48 \mathrm{a}$ & $79,27 \mathrm{a}$ & - \\
\hline
\end{tabular}

${ }^{1}$ ns: não-significativo; $*$ significativo a $5 \%$; ** significativo a $1 \%$ de probabilidade pelo teste da DMS.

${ }^{2}$ Médias seguidas da mesma letra, na mesma coluna e dentro de cada posição (centro ou externas), não diferem pelo teste de Duncan a 5\% de probabilidade. - Centro: número de plantas do biótipo indicado no centro da parcela, competindo com o número de plantas entre parênteses do biótipo oposto.

${ }^{4 /}$ Externas: número de plantas do biótipo indicado, competindo entre si e com a planta do biótipo oposto (1) no centro da parcela.

A taxa de transpiração (E) também não foi alterada quando uma planta isolada competia com um grupo de plantas do biótipo oposto. O mesmo ocorreu com o biótipo resistente quando localizado na periferia (Tabela 5). No entanto, quando plantas do biótipo suscetivel competiam entre si e contra uma única planta do biótipo resistente, observou-se incremento de E com o aumento da densidade de plantas, considerando que esse comportamento foi também observado para Gs (Tabela 2), pois essas variáveis estão estreitamente relacionadas. $O$ teste da DMS mostrou que a $\mathrm{E}$ foi superior para planta suscetivel somente quando ambos os biótipos foram avaliados na condição de planta isolada (Tabela 5), indicando mais uma vez que o biótipo suscetivel pode apresentar alguma vantagem no metabolismo.

O declínio de transpiração está associado ao fechamento dos estômatos, e variações na abertura estomática causam alterações no potencial hídrico, por atuarem sobre a $\mathrm{E}$ (Brodribb \& Hill, 2000). A planta tende a fechar os estômatos quando os niveis de luz estão abaixo da radiação fotossinteticamente ativa, ou para evitar o estresse hídrico (Cochard
Tabela 4 - Gradiente entre temperatura da folha e do ar $(\Delta \mathrm{T})$ dos biótipos resistente e suscetível ao glyphosate em condição de competição

\begin{tabular}{|c|c|c|c|}
\hline \multirow{2}{*}{$\begin{array}{l}\text { Posição e número } \\
\text { de plantas }\end{array}$} & \multicolumn{2}{|c|}{ Biótipos de azevém } & \multirow{2}{*}{ Diferença $^{1}$} \\
\hline & Resistente & Suscetível & \\
\hline Centro $^{3 /}$ & \multicolumn{3}{|c|}{$\Delta \mathrm{T}-{ }^{\circ} \mathrm{C}$} \\
\hline $1(0)$ & $0,99 \mathrm{a}^{2 /}$ & $2,49 \mathrm{a}$ & $-1,50 \mathrm{~ns}$ \\
\hline $1(1)$ & $0,00 \mathrm{a}$ & $1,57 \mathrm{a}$ & $-1,57 \mathrm{~ns}$ \\
\hline $1(2)$ & $0,86 \mathrm{a}$ & $1,85 \mathrm{a}$ & $-0,99 \mathrm{~ns}$ \\
\hline $1(3)$ & $1,50 \mathrm{a}$ & $1,29 \mathrm{a}$ & $+0,21 \mathrm{~ns}$ \\
\hline $1(4)$ & $1,95 \mathrm{a}$ & $1,43 \mathrm{a}$ & $+0,52 \mathrm{~ns}$ \\
\hline \multicolumn{4}{|l|}{ Externas $^{4 /}$} \\
\hline $0(1)$ & -- & -- & -- \\
\hline $1(1)$ & $0,87 \mathrm{a}$ & $0,80 \mathrm{a}$ & $+0,07 \mathrm{~ns}$ \\
\hline $2(1)$ & $0,09 \mathrm{a}$ & $1,96 \mathrm{a}$ & $-1,87 \mathrm{~ns}$ \\
\hline $3(1)$ & $1,19 \mathrm{a}$ & $1,19 \mathrm{a}$ & $+0,00 \mathrm{~ns}$ \\
\hline $4(1)$ & $0,36 \mathrm{a}$ & $1,45 \mathrm{a}$ & $-1,09 \mathrm{~ns}$ \\
\hline
\end{tabular}

${ }^{\perp}$ ns: não-significativo; $*$ significativo a $5 \%$; $* *$ significativo a $1 \%$ de probabilidade pelo teste da DMS.

${ }^{2}$ Médias seguidas da mesma letra, na mesma coluna e dentro de cada posição (centro ou externas), não diferem pelo teste de Duncan a 5\% de probabilidade.

${ }^{3}$ Centro: número de plantas do biótipo indicado no centro da parcela, competindo com o número de plantas entre parênteses do biótipo oposto.

4/ Externas: número de plantas do biótipo indicado, competindo entre si e com a planta do biótipo oposto (1) no centro da parcela.

et al., 2002). Todos esses parâmetros estão ligados numa relação de custo/benefício, pois a E também é um mecanismo de diminuição da $\Delta \mathrm{T}$. Os processos de transpiração e captura de $\mathrm{CO}_{2}$ só ocorrem quando os estômatos estão abertos, bem como a Gs. Devido ao calor latente de evaporação (aquele efetivamente usado para "aquecer" a água e possibilitar a evaporação), a transpiração tem poderoso efeito resfriador, importante na regulação da $\Delta \mathrm{T}$ (Farquhar \& Raschke, 1978).

A eficiência do uso da água (WUE) representa a quantidade de $\mathrm{CO}_{2}$ fixado para a produção de matéria seca em função da quantidade de água transpirada. Plantas do biótipo suscetivel ao glyphosate não mostraram alteração na WUE em função do incremento da densidade de plantas (Tabela 6). O mesmo ocorreu com o biótipo resistente quando em competição com outras plantas do mesmo biótipo e contra uma única planta do biótipo oposto. Quando plantas do biótipo resistente foram avaliadas isoladamente no centro da unidade experimental, mostraram superioridade sobre o biótipo suscetível sob as mesmas condições, com redução proporcional na WUE de acordo 
Tabela 5 - Taxa de transpiração (E) dos biótipos resistente e suscetível ao glyphosate em condição de competição

\begin{tabular}{|c|c|c|c|}
\hline \multirow{2}{*}{$\begin{array}{l}\text { Posição e número } \\
\text { de plantas }\end{array}$} & \multicolumn{2}{|c|}{ Biótipo de azevém } & \multirow{2}{*}{ Diferença $^{1 /}$} \\
\hline & Resistente & Suscetível & \\
\hline Centro $^{\underline{3}}$ & \multicolumn{3}{|c|}{$\mathrm{E}-\mathrm{mol} \mathrm{H}{ }_{2} \mathrm{O} \mathrm{m}^{-2} \mathrm{~s}^{-1}$} \\
\hline $1(0)$ & $1,98 \mathrm{a}^{2 /}$ & $4,40 \mathrm{a}$ & $-2,42 * *$ \\
\hline $1(1)$ & $3,08 \mathrm{a}$ & $3,25 \mathrm{a}$ & $-0,17 \mathrm{~ns}$ \\
\hline $1(2)$ & $2,65 \mathrm{a}$ & $3,45 \mathrm{a}$ & $-0,80 \mathrm{~ns}$ \\
\hline $1(3)$ & $2,16 \mathrm{a}$ & $3,54 \mathrm{a}$ & $-1,38 \mathrm{~ns}$ \\
\hline $1(4)$ & $2,17 \mathrm{a}$ & $3,74 \mathrm{a}$ & $-1,57 \mathrm{~ns}$ \\
\hline \multicolumn{4}{|l|}{ Externas ${ }^{\underline{4}}$} \\
\hline $0(1)$ & -- & -- & -- \\
\hline $1(1)$ & $3,67 \mathrm{a}$ & $2,36 \mathrm{~b}$ & $+1,31 \mathrm{~ns}$ \\
\hline $2(1)$ & $4,31 \mathrm{a}$ & $2,98 \mathrm{~b}$ & $+1,33 \mathrm{~ns}$ \\
\hline $3(1)$ & $3,64 \mathrm{a}$ & $3,76 \mathrm{ab}$ & $-0,12 \mathrm{~ns}$ \\
\hline $4(1)$ & $3,35 \mathrm{a}$ & $5,23 \mathrm{a}$ & $-1,88 \mathrm{~ns}$ \\
\hline
\end{tabular}

I/ ns: não-significativo; $*$ significativo a $5 \%$; ** significativo a $1 \%$ de probabilidade pelo teste da DMS

2ొ Médias seguidas da mesma letra, na mesma coluna e dentro de cada posição (centro ou externas), não diferem pelo teste de Duncan a 5\% de probabilidade.

3/Centro: número de plantas do biótipo indicado no centro da parcela, competindo com o número de plantas entre parênteses do biótipo oposto.

4/Externas: número de plantas do biótipo indicado, competindo entre si e com a planta do biótipo oposto (1) no centro da parcela.

com o no número de plantas do biótipo suscetivel com as quais competia (Tabela 6). A maior WUE observada no biótipo resistente na ausência de competição pode ser indicativo de que algum mecanismo nas plantas do biótipo resistente poderia estar proporcionando menor transpiração durante os periodos de abertura estomática. Uma possibilidade seria de que a condução de água das raízes até a parte aérea das plantas no biótipo resistente poderia ser mais lenta ou menos eficiente, o que provavelmente resultaria em alteração na E. No entanto, a $\mathrm{E}$ não foi diretamente afetada nesses tratamentos (Tabela 5), mas a $\mathrm{E}_{\mathrm{an}}$ (Tabela 3) foi alterada.

Além do exposto, $\mathrm{E}$ e $\mathrm{E}_{\text {an }}$ estão intimamente relacionadas, podendo ser considerado que uma responda pela outra. Embora E não tenha se alterado, $\mathrm{E}_{\text {an }} \mathrm{o}$ foi, e estas variáveis apresentam correlação em nivel de $1 \%$. A Gs e a E também estão correlacionadas em nivel de $1 \%$ (Tabela 7), visto que a transpiração é determinante primária do balanço de energia e status hídrico da planta (Sinclair et al., 1975). A E é determinada principalmente por Gs e duas variáveis físicas: radiação e déficit de saturação atmosférica (Raschke \& Zeevaart, 1976; Hunt
Tabela 6 - Eficiência do uso da água (WUE) dos biótipos resistente e suscetível ao glyphosate em condição de competição

\begin{tabular}{|c|c|c|c|}
\hline \multirow{2}{*}{$\begin{array}{l}\text { Posição e número } \\
\text { de plantas }\end{array}$} & \multicolumn{2}{|c|}{ Biótipo de azevém } & \multirow{2}{*}{ Diferença $^{1}$} \\
\hline & Resistente & Suscetível & \\
\hline Centro $^{3 /}$ & \multicolumn{3}{|c|}{ WUE - $\mathrm{mol} \mathrm{CO}_{2} \mathrm{~mol} \mathrm{H}_{2} \mathrm{O}^{-1}$} \\
\hline $1(0)$ & $7,63 \mathrm{a}^{2 !}$ & $3,08 \mathrm{a}$ & $+4,55 * *$ \\
\hline $1(1)$ & $5,07 \mathrm{ab}$ & $2,91 \mathrm{a}$ & $+2,16 *$ \\
\hline $1(2)$ & $3,92 \mathrm{~b}$ & $2,18 \mathrm{a}$ & $+1,74 \mathrm{~ns}$ \\
\hline $1(3)$ & $4,28 \mathrm{~b}$ & $2,51 \mathrm{a}$ & $+1,77 \mathrm{~ns}$ \\
\hline $1(4)$ & $4,12 \mathrm{~b}$ & $2,27 \mathrm{a}$ & $+1,85 \mathrm{~ns}$ \\
\hline \multicolumn{4}{|l|}{ Externas $^{4}$} \\
\hline $0(1)$ & -- & -- & -- \\
\hline $1(1)$ & $3,49 \mathrm{a}$ & $3,91 \mathrm{a}$ & $-0,42 \mathrm{~ns}$ \\
\hline $2(1)$ & $3,02 \mathrm{a}$ & $3,39 \mathrm{a}$ & $-0,37 \mathrm{~ns}$ \\
\hline $3(1)$ & $3,11 \mathrm{a}$ & $2,22 \mathrm{a}$ & $+0,89 \mathrm{~ns}$ \\
\hline $4(1)$ & $2,11 \mathrm{a}$ & $1,88 \mathrm{a}$ & $+0,23 \mathrm{~ns}$ \\
\hline
\end{tabular}

$\sqcup$ ns: não-significativo; * significativo a $5 \%$; ** significativo a $1 \%$ de probabilidade pelo teste da DMS

${ }^{2 \prime}$ Médias seguidas da mesma letra, na mesma coluna e dentro de cada posição (centro ou externas), não diferem pelo teste de Duncan a 5\% de probabilidade.

${ }^{3 /}$ CENTRO: número de plantas do biótipo indicado no centro da parcela, competindo com o número de plantas entre parênteses do biótipo oposto.

4/ EXTERNAS: número de plantas do biótipo indicado, competindo entre si e com a planta do biótipo oposto (1) no centro da parcela.

et al., 1985). As demais variáveis não se correlacionaram entre si (Tabela 7).

No biótipo resistente, conforme a WUE foi reduzida com o aumento na densidade do biótipo oposto, ocorreu incremento na $\mathrm{E}_{\text {an }}$, ou seja, enquanto a eficiência do uso da água foi reduzida, a pressão de vapor de água na câmara subestomática foi incrementada. Muito embora a $\mathrm{E}$ não tenha se alterado, provavelmente quando os estômatos se abrem, a água contida em larga escala na forma de vapor na câmara subestomática se perde rapidamente, os estômatos se fecham e pouco $\mathrm{CO}_{2}$ entra para o mesófilo. Esse fator, aliado a uma possivel redução

Tabela 7 - Matriz de correlação entre as variáveis estudadas nos biótipos resistente e suscetível ao glyphosate em condição de competição

\begin{tabular}{|l|c|c|c|}
\hline \multicolumn{1}{|c|}{ Variáveis } & Interação & Variáveis & Interação \\
\hline Gs $\times \mathrm{E}_{\mathrm{an}}$ & $+0,621 \mathrm{~ns}$ & $\mathrm{E}_{\mathrm{an}} \times \mathrm{E}$ & $+0,861 * *$ \\
\hline Gs $\times \Delta \mathrm{T}$ & $-0,151 \mathrm{~ns}$ & $\mathrm{E}_{\mathrm{an}} \times \mathrm{WUE}$ & $+0,232 \mathrm{~ns}$ \\
\hline Gs $\times \mathrm{E}$ & $+0,820 * *$ & $\Delta \mathrm{T} \times \mathrm{E}$ & $+0,293 \mathrm{~ns}$ \\
\hline Gs $\times \mathrm{WUE}$ & $+0,119 \mathrm{~ns}$ & $\Delta \mathrm{T} \times \mathrm{WUE}$ & $-0,360 \mathrm{~ns}$ \\
\hline $\mathrm{E}_{\mathrm{an}} \times \Delta \mathrm{T}$ & $+0,429 \mathrm{~ns}$ & $\mathrm{E} \times \mathrm{WUE}$ & $-0,013 \mathrm{~ns}$ \\
\hline
\end{tabular}

ns - interação não-significativa; ** interação significativa a $1 \%$ de probabilidade. 
na capacidade de bombeamento de água das raizes para as folhas, poderia estar associado ao maior tempo de fechamento estomático (necessário para repor a quantidade de água nas folhas) e ao menor crescimento normalmente observado no biótipo resistente (Vargas et al., 2005).

O biótipo resistente incorpora menos $\mathrm{CO}_{2}$, pois os estômatos se fecham rapidamente para evitar desidratação demasiada e acabam capturando quantidades relativamente pequenas de $\mathrm{CO}_{2}$, o que justifica o menor acúmulo de massa no biótipo resistente. Por sua vez, a menor velocidade de condução de água das raízes para a parte aérea limita a perda de água àquela contida na câmara subestomática durante o periodo de abertura dos estômatos, o que torna o biótipo resistente mais eficiente no uso da água que o suscetivel, tanto na presença como na ausência de competição, embora com menor capacidade de incorporação de $\mathrm{CO}_{2}$. Uma das razões para o biótipo resistente ser mais eficiente que o suscetivel quanto ao uso da água pode ser a menor eficiência na absorção e fluxo de água pela corrente transpiratória e o menor tempo de abertura estomática.

\section{LITERATURA CITADA}

ATKIN, O. K. et al. Leaf respiration of snow gum in the light and dark. Interactions between temperature and irradiance. Plant Physiol., v. 122, p. 915-923, 2000.

BAPTISTA, J. M. et al. Programa nacional para o uso eficiente da água. Lisboa: Instituto Superior de Agronomia, 2001. $212 \mathrm{p}$.

BRODRIBB, T. J.; HILL, R. S. Increases in water potential gradient reduce xylem conductivity in whole plants. Evidence from a low-pressure conductivity method. Plant Physiol., v. 123, p. 1021-1028, 2000.

BRODRIBB, T. J.; HOLBROOK, N. M. Stomatal closure during leaf dehydration, correlation with other leaf physiological traits. Plant Physiol., v. 132, p. 2166-2173, 2003.

COCHARD, H. et al. Unraveling the effects of plant hydraulics on stomatal closure during water stress in walnut. Plant Physiol., v. 128, p. 282-290, 2002.
DRAKE, B. G.; SALISBURY, F. B. After effects of low and high temperature pretreatment on leaf resistance, transpiration, and leaf temperature in Xanthium. Plant

Physiol., v. 50, p. 572-575, 1972.

FARQUHAR, G. D.; RASCHKE, K. On the resistance to transpiration of the sites on transpiration within the leaf. Plant Physiol., v. 61, p. 1000-1005, 1978.

FERREIRA, E. A. et al. Glyphosate translocation in Italian ryegrass biotypes (Lolium multiflorum). Planta Daninha, v. 24, p. 365-370, 2006.

HUNT, E. R. et al. Effects of nitrate application on Amaranthus powellii Wats II. Stomatal response to vapor pressure difference is consistent with optimization of stomatal conductance. Plant Physiol., v. 79, p. 614-618, 1985.

MELO, P. T. B. S. et al. Comportamento de populações de arroz irrigado em função das proporções de plantas originadas de sementes de alta e baixa qualidade fisiológica. R. Bras. Agrociência, v. 12, p. 37-43, 2006.

PEREIRA-NETTO, A. B. Crescimento e desenvolvimento. In: WACHOWICZ, C. M.; CARVALHO, R. I. N. (Eds.) Fisiologia vegetal - produção e pós-colheita. Curitiba: Champagnat, 2002. p. 17-42.

PIMENTEL GOMES, F. P. A estatística moderna na pesquisa agropecuária. Piracicaba: POTAFOS, 1987. 160 p.

RASCHKE, K.; ZEEVAART, J. A. D. Abscisic acid content, transpiration, and stomatal conductance as related to leaf age in plants of Xanthium strumarium L. Plant Physiol., v. 58, p. $169-174,1976$.

ROMAN, E.S. et al. Resistência de azevém (Lolium multiflorum) ao herbicida glyphosate. Planta Daninha, v. 22, p. 301-306, 2004.

SINCLAIR, T. R. et al. Water use efficiency of field-grown maize during moisture stress. Plant Physiol., v. 56, p. 245249, 1975.

VARGAS, L. et al. Identificação de biótipos de azevém (Lolium multiflorum) resistentes ao herbicida glyphosate em pomares de maçã. Planta Daninha, v. 22, p. 617-622, 2004.

VARGAS, L. et al. Alteração das características biológicas dos biótipos de azevém (Lolium multiflorum) ocasionada pela resistência ao herbicida glyphosate. Planta Daninha, v. 23, p. 153-160, 2005.

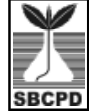

